\title{
Rethinking Media and Technology: What the Kennedy-Nixon Debate Myth Can Really Teach Us
}

\section{Paul Myron Hillier, University of Tampa, USA}

\begin{abstract}
The presumption that communication technologies - TV, the Internet, social media - have fundamentally changed society has a deep cultural resonance. Indeed, the predominant framework for theorizing "media" - within both the academy and in popular culture more broadly - is rooted in technological determinist presumptions. The primary goal of this article is to challenge this framework, to demonstrate the ways it is incompatible with critical theory, and to make as case for a method and tradition that more productively problematizes technology itself. Taking on one of the most repeated claims and examples for the "effects" of media technologies, the Kennedy-Nixon debate, the article makes a case that a limited, binary theoretical model has fundamentally influenced the deductions. What's at stake here is how to properly theorize media technologies and propose solutions to social problems and issues.
\end{abstract}

Keywords: Marshal McLuhan; Raymond Williams; Technological Determinism; KennedyNixon Debate; Critical Theory; Cultural Studies 
The notion that specific technologies have altered society has a far-reaching resonance. Explanations of the printing press, clocks, steam engine, cotton gin, automobiles, and computers, as popular examples, are quite often presented in terms of how they produced social change. Communication technologies - "media" - are especially understood in this way. Interactive TV, the Internet, social networking, and smartphones are all said to have changed or will change the ways we communicate if not the world. No question, the predominant framework for theorizing "media" - within both the academy and in popular culture more broadly - is rooted in technological determinist presumptions. McLuhan's “the medium is the message" isn't a fringe paradigm, a conception that sits on the outside of society and is held by a perceptive few - as the proponents of this tradition often like to position themselves - but is rather the guiding intellectual and theoretical tradition for studying forms of media and technology. Far from being a truly critical paradigm, though, this approach proves limiting if not seriously misguided in terms of critical analysis and, most of all, in thinking about media's role in relation to social problems.

The primary goal of this article is to challenge the predominate framework for understanding "media," to demonstrate the ways it is incompatible with critical theory, and to make as case for a method and tradition that more productively problematizes technology itself. Taking on one of the most repeated claims and examples for the "effects" of media technologies - the Kennedy-Nixon debate - the article makes a case that a limited, binary theoretical model has fundamentally influenced the deductions. While scholars like Slack and Wise have put forward compelling critiques of technological determinism within a more recent tradition of Cultural Studies, an even earlier line of Marxist social theory still proves to be a productive way to critically theorize media technologies and critical praxis. ${ }^{1}$ Replacing "technology" with “practice," Raymond Williams in particular helps shift our attention to intention as part of uneven hierarchies of power. The starting point here begins with social activities and formations as opposed to technologies, all in relationship to political economic factors that play a determining - not a determinist - role. Seeing media and related technology as social practices - not in terms of specific objects, effects, singular problems or answers - can be to recover human agency and to emphasize the central political economic issues at stake. Indeed, what's at stake here is how to both theorize media technologies and propose solutions to problematic social issues. New ways of using or sharing technologies are not the answer. Addressing economic and social inequality is far more crucial. 


\section{The Kennedy-Nixon Debate Myth}

One of the more pervasive stories that is said to provide clear evidence for the effects of a communication technology has been the infamous Kennedy-Nixon debate. ${ }^{2}$ In that first-ever televised presidential debate between the youthful, "telegenic" Senator John Kennedy of Massachusetts and the now-well-noted makeup-free Vice President Richard Nixon, Erika Tyner Allen of The Museum of Broadcast Communications provides the typical story, writing, "those who heard the first debate on the radio pronounced Nixon the winner. But the 70 million who watched television saw a candidate still sickly and obviously discomforted by Kennedy's smooth delivery and charisma. Those television viewers focused on what they saw, not what they heard. Studies of the audience indicated that, among television viewers, Kennedy was perceived the winner of the first debate by a very large margin.”3

Kennedy defeated Nixon primarily because of how they appeared on TV. Television exposed Nixon as uncomfortable, perhaps sinister while Kennedy came across articulate and sincere. And to provide evidence that television itself made the difference, a good many go as far as to say changed the nature of politics itself, many scholars and commentators point to this notion that the majority of people who listened to the debate on the radio thought Nixon "won" while those who watched the debate on TV declared Kennedy the "winner." Indeed, this claim is made so often and by so many different people that one might get the impression there has to be something more than anecdotal evidence to support the argument.

Almost thirty years ago Vancil and Pendell critiqued the myth that radio and television audiences came to different conclusions about which candidate "won” the first KennedyNixon debate, yet the claim and reading of the event remains both widespread and strong. Indeed, a comprehensive list of the texts that make the claim that radio and television audiences disagreed on the debate since Vancil and Pendell's article would be very long. "One of the most perplexing legacies of the first Kennedy-Nixon debate is the claim that radio listeners and television viewers came to opposite conclusions about the debate winner," they wrote in their 1987 article, "The Myth of Viewer-Listener Disagreement in the First Kennedy-Nixon Debate.”4 Throughout their study, Vancil and Pendell rather convincingly and exhaustively demonstrate that none of the empirical research done during the period supports or even reports this viewer-listener disagreement. In fact, as the authors' address all of the major polling organizations surveys, they confirm that the polls "could not have shown 
Nixon as having 'a clear advantage' among radio listeners” because none of the organizations distinguished between the radio and television audience to begin with. The authors also trace the major citations and sources for this claim in order to well establish they're all personal opinion rather than statistical evidence.

While questions of who really did “win,” audiences' interpretations of political discourse in the age of TV are somewhat interesting, how the debate has been understood highlights a significant, problematic presumption about the role and function of communication technologies in society. The debate has indeed become this key, obvious moment that a good many critics and scholars point to in order to illustrate the demonstrable differences between communication technologies and their "effects". The claim that the mediums of radio and television have different "effects," and that the Kennedy-Nixon debate clearly illustrates the social and cultural consequence of television, for good or ill, has been commonplace, even logical to presume. The debate myth is so pervasive, though, precisely because the assumption of a viewer-listener disagreement entirely in line with a widely accepted theoretical approach and general understanding of media and technology that informs this kind of reading. It's an approach and understanding that deserves serious questioning (if not rejection). Why does this myth have such cultural currency?

\section{Cause and Effect: Mcluhan's Vision (Problem)}

"Nixon's meteoric rise from the unemployment line to the vice presidency in six quick years would never have happened if TV had come along 10 years earlier," Hunter S. Thompson wrote of Nixon. "When Nixon finally had to face the TV cameras for real in the 1960 presidential campaign debates,” Thompson continues, "he got whipped like a red-headed mule. Even die-hard Republican voters were shocked by his cruel and incompetent persona. Interestingly, most people who heard those debates on the radio thought Nixon had won. But the mushrooming TV audience saw him as a truthless used-car salesman, and they voted accordingly." 5 CNN describes Nixon and debate less caustically on their website, asserting, "What everyone remembers is the first debate, where the telegenic Kennedy won the image battle over Nixon who, recovering from the flu, appeared pale and refused make-up. ... One study concluded that those who heard the debate on the radio thought the contest to be a draw, while those who watched the broadcast thought Kennedy the clear winner."6 
Again, as already noted, Vancil and Pendell well demonstrate there's no empirical evidence or "study" to support this claim of a viewer-listener disagreement during the debate. While the first claims that people who watched the debate on television differed in perception from those who listened on the radio can be found in speculative newspaper commentary immediately following the debate, considering the body of literature, both popular and scholarly, up to the present day that make this claim, one name appears again and again as both direct and indirect citations: Marshal McLuhan. ${ }^{7}$ Surveying this body of work, David M. Lubin points out, "It was McLuhan who advanced the notion that Kennedy had triumphed over Nixon in the televised debates because his relative casualness and nonchalance were so much easier for viewers to watch - that is, to invite into their living rooms - than his rival's over insistent, almost hectoring, style of debate.” ${ }^{\prime 8}$ And, indeed, McLuhan devoted a fair number of pages to the debate in his seminal 1964 text, Understanding Media.

While television was of central importance to McLuhan, his theory of the way television operates in society is part of a much larger conception of communication technologies or "mediums." McLuhan claimed that the way a culture primarily communicates, the technologies a society uses to do so, has a profound if not structural effect on the culture and society itself. McLuhan argues, "Societies have always been shaped more by the nature of the media by which men communicate than by the content of the communication." 9 For McLuhan, “The medium is the message’ means, in terms of the electronic age, that a totally new environment has been created."10 Simply put, McLuhan's theory of communication technologies is that they fundamentally shape and can even change social conditions. "The effects of technology do not occur at the level of opinions or concepts,” McLuhan contends, "but alter sense ratios or patterns of perception steadily and without any resistance."11

At the root of McLuhan's methodology is a formulation that conceptualizes technologies mediums - as independent properties. “Technology” - a medium - is theorized in one sphere while society and culture are in another. The point is to study the relationship between the two with an emphasis on the formal elements of the technology/medium. No question, McLuhan very clearly puts forward that different technologies produce different effects, writing, "Concern with effect rather than meaning is a basic change of our electric time, for effect involves the total situation, and not a single level of information movement." ${ }^{\text {12 }}$ It is within this theoretical framework that McLuhan makes his claim that "In the Kennedy-Nixon 
debates, those who heard them on the radio received an overwhelming idea of Nixon's superiority." ${ }^{\prime 3}$ While it is important to emphasize McLuhan's claim is entirely speculative he provides no empirical evidence for this assertion - it is just as essential to point out in his reading of the debate content and context are irrelevant, or at least trivial, because the technology itself is the real message. "Radio affects most people intimately, person-toperson," McLuhan declares, so people who listened to Nixon on the radio were naturally affected one way while those who watched the debate on television another way.

Vision is a crucial element in McLuhan's formulation and approach, indeed the whole body of his work, as it is with many other accounts of television's role in the Kennedy-Nixon debate myth. The claim that Nixon's visual appearance caused people to look unfavorable upon him, that he "lost" the debate because of the way he looked is problematic on a number of levels. Addressing this point, Vancil and Pendell sensibly note that "Appearance problems, such as Nixon's perspiring brow, could have had a negative impact on viewer perceptions, but it is also possible for viewers to be sympathetic to such problems, or to interpret them as evidence of attractive or desirable qualities." ${ }^{14}$ Appearance alone does not lead one to any natural or essential conclusions. One’s person's "used-car salesman” can be another's benevolent friend. Reading a person's perspiration as evidence of a dishonest character isn't a natural reaction to a televised image but rather a socially constructed one.

It is quite tempting to address McLuhan and like arguments at the same level of sense. A whole set of complicating and counter positions can be imagined. On what basis can we really claim what we see trumps what we hear? Would this be true in every instance and in all contexts? Someone eloquently advocating criminal mischief on radio has more of an effect on those who listen as opposed to those who see the person speaking is an obese man in a burlap sack? But critiquing television or any technology in terms of sense is to miss the larger picture. Raymond Williams rightfully perceived that in these kinds of analyses, "All media operations are in effect dissocialized; they are simply physical events in an abstracted sensorium, and distinguishable only by their variable sense-ratios.” ${ }^{\text {15 }}$ Situating television, or any "technology," in and as part of a social, cultural, and economic conditions is crucial. What we have are a network of social relationships and hierarchies of access and power that make up our lives, not a system of sounds, appearances, and images. The championing of a kind of polished image, a blue suit, a youthful completion, certain types of gestures and a 
particular body-image did not happen because of television, but because of social, cultural, political and economic goals, desires, and ends, all advanced and chosen by certain people within specific contexts and for particular reasons.

McLuhan's approach, again, rests on conceptualizing television as an independent, formal property. But isolating television as an object of study itself, as a categorically definable form can obscure if not entirely miss the larger social conditions in which television is entirely embedded. No technology operates outside of society. Indeed, no technology even has any meaning outside of society. Television is not independent of people and social situations. Television, radio, “social media," smartphones have no effect by themselves. Every technology is entirely dependent upon people, society, and culture to give it meaning and use, and those meanings and use are never fixed or without contention. So if television and other "mediums" have no fixed, essential, or deterministic qualities outside of society, then where one might begin is by first paying attention to social factors - how the technology is used and regarded, by whom, in what contexts, and for what means and ends. This isn't a common approach, though, because conceptualizing technologies as independent properties capable of observable effects is very much naturalized in the ways people think about media.

\section{The Beginning Questions}

When Williams predicted that “[t]he particular rhetoric of McLuhan's theory of communications is unlikely to last long," he was likely referring to McLuhan's jazzy style and the scholar's developing hipster status. Although McLuhan retains a place in pop-culture and his work has a well established a place in the academy, there's no reason to believe this would have surprised Williams today. Williams understood that McLuhan's approach complimented the larger social order, that this was all entirely in line with the kind of social scientific research that both media institutions and communication departments in the academy favor. What is tad remarkable, however, is that McLuhan has now been with us for decades yet his and like theories are still positioned as avant-garde, seen as "outsider" or against the grain. For when taken as a whole, McLuhan's method and a social scientific approach - again, the well-established norm for studying media "effects - are really two sides of the exact same coin. 
"How does television affect political behavior? I address this question by describing an experiment where participants either watched a televised version of the first Kennedy-Nixon debate or listened to an audio version,” writes James N. Druckman in his study, "The Power of Television Images: The First Kennedy-Nixon Debate Revisited.” Interestingly, it is a social scientist like Druckman who recognizes the debate myth, writing "I used this debate in part because despite popular conceptions, there is no extant evidence that television images had any impact on audience reactions."16 What his experiment on college-age students who presumably hadn't seen nor heard of the debate prior to his tests concludes is that, indeed, radio and television viewers came to different conclusions about the debate, that the technologies had different effects, and that "Kennedy may have done better on television because of his superior image." So the empirical "proof” for a technological effect has been statistically verified.

While Druckman's study is fascinating on a number of levels, and can be critiqued if not challenged in a variety of ways (is what's observed the result of a technology or a social expectation?), what deserves attention here are the similarities between this kind of social scientific method and that of McLuhan and like scholars. Both treat television as an abstract, independent object of study and, fundamentally, both begin with similar if not identical kinds of questions: "How does television effect people or political behavior?” If this is the way the question is asked, it is difficult to provide an answer that doesn't privilege technological effects. You can answer the question with a survey or you can talk about psychic effects of the technology, conclusions can range from libratory to dire, yet the deeply engrained formulation between a technology and society remains: A technology's formal features obviously produces effects. There's no questioning that presumption. It is built into the way the questions are posed. Regardless of the answers, the questions begin with a debatable position. This is more than a theoretical issue alone, but rather speaks to the foremost way of understanding the role and function of particular kinds of media in society. The beginning questions are exceedingly important, for questions themselves are as socially and culturally constituted as any of the answers arrived at. As Williams wrote, “The most precise and discriminating local study of 'effects' can remain superficial if we have not looked into the notions of cause and effect, as between a technology and a society, a technology and a culture, a technology and a psychology, which underlie our questions and may often determine our answers." ${ }^{17}$ Note that debate myth itself can be challenged without seriously 
undermining the determinist logic that underlies how media and technology are widely approached. New accounts of the debate might take into consideration the absence of empirical evidence that supports this listener-viewer disagreement. Druckman's study might be mentioned. But these are unlikely to challenge the ways people generally conceive of media. The root technological determinist formulations in these approaches need to be closely questioned, so both the debate myth itself and corresponding system of thought are made problematic.

Williams articulated one of the more complete critiques of technological determinism in media and communication studies. While "mobile privatization" and "flow" are two of the more widely applied concepts from his seminal text Television, ${ }^{18}$ it is more his critical method for studying media and technology in society that's particularly valuable and perceptive. Asking us to focus on the implicit assumptions that inform the questions we ask about a technology like television is just one of the many important points Williams emphasizes. He also keen critic of McLuhan and the tradition from which he's a part, now more commonly called “Media Ecology,” pointing out it has such cultural currency because it complements an existing social order. Williams wrote of McLuhan's deductions and theory, “It is hardly surprising that this conclusion has been welcomed by the 'media-men' of the existing institutions. It gives the gloss of avant-garde theory to the crudest versions of their existing interests and practices, and assigns all their critics to pre-electronic irrelevance.”"19 One of the major problems with determinist approaches to media is the extent to which the industry behind the social form is outside the theoretical frame of reference. Considering ideology in terms of "the political function of ideas in society," technological determinism is ideological. ${ }^{20}$ It works in great part - and, to be sure, ideology does not always operate at the level of conscious intention - to the benefit of the status quo.

Technological determinism masks or at least distracts us from questions of ownership, control, and intention. Treating specific forms of communication - TV, “The Internet,” books - as technologies is far too simplistic if not entirely mistaken. Take a favorite example of self-avowed technological determinists, Lewis Mumford's notion of the clock. "The clock, not the steam engine," Mumford famously wrote, "is the key machine of the modern industrial age."21 Mumford reduces profound and contested political economic transformations to a matter of timekeeping. What's really more important, the clock itself or 
the social enforcement of the clock? It's economic factors that help shape and determine not in any fixed, determinist sense - social relations, not a form of "technology." The transformation of society is an economic and political struggle, not a technological one. Seeing technologies as entirely part of a set of social relationships can not only be to recover human agency but to also highlight the material fact that new uses or forms of technology will not in themselves change or even address social issues. Simply put, critical theory and McLuhan's line of thought are entirely incompatible.

\section{Towards (A Return to) Practice and Praxis}

In his popular book, No Sense of Place: The Impact of Electronic Media on Social Behavior, Joshua Meyrowitz repeats the widely shared belief that "those who watched the NixonKennedy debates on television tended to agree that Kennedy had won, while many of those who listened to the debates on radio thought that Nixon had won." ${ }^{\text {22 }}$ We can follow the footnote to read Meyrowitz supports the claim by stating, “The point has been mentioned by many writers, including Mickelson, 1972, p.207” and critique it by pointing out that Vancil and Pendell address this very cite and show it is, like all the others, speculative and without empirical proof. ${ }^{23}$ We can also address Meyrowitz's reading of Nixon, that "His finely tuned verbal arguments were often undermined by a clenched fist, shifty eyes, and a contemptuous scowl," by again emphasizing that visual features alone to do constitute a dominant reading nor is it sufficient evidence for a widespread social effect. ${ }^{24}$ The same can be said when Steven Johnson declares in his own popular book, Everything Bad is Good for You: How Today's Popular Culture is Actually Making Us Smarter, that "Nixon lost on TV because he didn't look like someone you would want as president, and where emotional IQ is concerned, looks don't always deceive.”25 As determinists in debt to McLuhan, Meyrowitz and Johnson aren't “outliers.” They're the norm. They represent how the majority of people conceive and explain media and technology.

In the appendix of his book, Meyrowitz writes "Williams and others ... focus on the political and economic structures and their interactions with communication technologies. I suggest, however, that regardless of the reasons for its development, the particular combination of a communication technology and a configuration for its use (a combination that might be called a 'techno/use') often has many social consequences that are not directly related to the intentions of powerful political and economic forces. Indeed, new media may have profound 
effects on the economic and political forces." ${ }^{26}$ First, it should be noted that this is an incomplete reading of Williams. Williams well recognized and appreciated unintended consequences. More substantially, though, what Meyrowitz and other determinists too often miss are the consequences of their conceptual approach and model. As Jennifer Daryl Slack and J. Macgregor Wise cogently note, "the relationship between culture and technology is every bit as much a theoretical problem as it is a task of descriptions, and technological practitioners are often unaware of the work being performed by their own theoretical assumptions."27 David Harvey's thoughtful self-analysis is relevant, as well, writing, "I recognized that definitions could dictate conclusions and that a system of thought erected on fixed definitions and fixed categories and relationships could inhibit rather than enhance our ability to comprehend the world." ${ }^{28}$ The Kennedy-Nixon debate myth is just one representative example of a pervasive cultural logic that needs to be challenged and critiqued, since it has serious social and cultural implications.

These repeated accounts of the Kennedy-Nixon debate might be seen in a direct relation to the public service announcements urging kids and young adults to read, which too highlights the extent of determinist thinking. Both arguments locate cognitive transformations in a formal "technology," the kind of logic that leads Johnson to declare, "I believe the printed word remains the most powerful vehicle for conveying complicated information - though the electronic word is starting to give books a run for their money." ${ }^{29}$ What's most problematic in these arguments, though, is the model of society it presents. When society is presented as structured not on social relationships and material conditions but on forces or technologies outside and apart from people, meaning and possibilities become limited if not made for us. Content and social conditions cannot be easily dismissed, though, and can be a set of questions that play a role in countering determinist formulations. When we consider those well-meaning ads and posters that promote "reading," as if reading itself leads to knowledge, this perhaps becomes clear. Of course, it is not that one reads, it is what and how one reads, in what social contexts that are ultimately important. Put another way, the task is to reconceptualize media and technology as a practice and activity within socio-economic conditions.

As Williams perceived of the ways we talk about a technology, "It is either a self-acting force which creates new ways of life, or it is a self-acting force which provides materials for new 
ways of life. These positions are so deeply established, in modern social thought, that it is very difficult to think beyond them."30 "The media” and technology are treated as if they're some abstract force in the world, as if they're somehow disconnected from people, culture, and contexts and not the contested, political struggle that they are (or should be). A consequence of determinist thinking is that attention becomes fixed in the wrong areas and places. As Karen Sternheimer writes, "Despite the common-sense view that media must be at least partly to blame for ... social problems, the evidence suggests that there are many more important factors that create serious social problems in the United States today."31 The media or technology itself is not the problem or solution. Economic opportunities, mental health, equal justice, comfort and security are all more fundamental social issues. Treating media and technology as political cultural practices as a part of these more fundamental social issues not as formal objects of study in themselves - is a step down the road to seeing that we shape and make our world, and that new social relationships are not outside our control.

\section{References}

${ }^{1}$ Jennifer Daryl Slack and J. Macgregor Wise, “Cultural Studies and Technology,” in The Handbook of New Media, L. Lievrouw OC S. Livingstone (eds), (Thousand Oaks, CA: Sage Publications, 2002

${ }^{2}$ The first debate between the two candidates took place on September 26th, 1960.

${ }^{3}$ Erika Tyner Allen, “The Kennedy-Nixon Presidential Debates, 1960,” The Museum of Broadcast Communications, http://www.museum.tv/eotv/kennedy-nixon.htm

${ }^{4}$ David L. Vancil and Sue D. Pendell, "The Myth of Viewer-Listener Disagreement in the First Kennedy-Nixon Debate,” in Central State Speech Journal, Spring 1987, 38/1. Pgs. 16-27

${ }^{5}$ Hunter S. Thompson, “He Was a Crook,” CounterPunch, http://www.counterpunch.org/thompson02212005.html

${ }^{6}$ CNN Website, “1960 Presidential Debates,”http://wwwcgi.cnn.com/ALLPOLITICS/1996/debates/history/1960/

${ }^{7}$ Vancil and Pendell locate primary citations for this radio-television viewers' disagreement to as early as the day after the debate, anecdotal to be sure.

${ }^{8}$ David M. Lubin, Shooting Kennedy: JFK and the Culture of Images, (Berkeley and Los Angeles, California, University of California Press, 2003), 135-136 
${ }^{9}$ Marshall McLuhan, Medium is the Massage (New York, London, and Toronto: Bantam Books, 1967), 6

${ }^{10}$ Marshall McLuhan, Understanding Media (New York: Signet Books, 1964), ix

${ }^{11}$ McLuhan, Understanding Media, 33

12 McLuhan, Understanding Media, 39

${ }^{13}$ McLuhan, Understanding Media, 261

${ }^{14}$ Vancil and Pendell, 17

${ }^{15}$ Raymond Williams, Television: Technology and Cultural Form (London and New York: Routledge Classics, 2003),131

${ }^{16}$ James N. Druckman, “The Power of Television Images: The First Kennedy-Nixon Debate Revisited,” in The Journal of Politics, Vol. 65, No. 2, May 2003, Pp. 559-571

${ }^{17}$ Williams, 2

${ }^{18}$ A survey of the major anthologies in television studies confirms this assertion. For example, look at the references to Williams in Newcomb’s Television: The Critical View (2006) or Spiegl's Television After TV (2004) and you'll see all of the authors here focus on "flow" or "mobile privatization."

${ }^{19}$ Williams, 131

${ }^{20}$ Quote taken from Terry Eagleton, Marx and Freedom (London: Orion Publishing Group, 1997), 13

${ }^{21}$ Lewis Mumford, Technics and Civilization, (New York: Harcourt, Inc., 1934), 14

22 Joshua Meyrowitz, No Sense of Place: The Impact of Electronic Media on Social Behavior, (Oxford University Press, 1985), 281

${ }^{23}$ Meyrowitz, 367

${ }^{24}$ Meyrowitz, 292

${ }^{25}$ Steven Johnson, Everything Bad is Good for You: How Today’s Popular Culture us

Actually Making Us Smarter, (New York: Riverhead Books, 2005), 103

${ }^{26}$ Meyrowitz, 332

${ }^{27}$ Slack and Wise, 485

${ }^{28}$ David Harvey, Social Justice and the City, The Johns Hopkins University Press, Baltimore, Maryland, 1973, Page 12

${ }^{29}$ Johnson, 2

${ }^{30}$ Williams, 2 
${ }^{31}$ Karen Sternheimer, Connecting Social Problems and Popular Culture Why Media is Not the Answer, (Westview Press, a Member of the Perseus Books Group, 2013), 2 